\title{
Taurodontia-absent teeth-sparse hair syndrome
}

INSERM

\section{Source}

INSERM. (1999). Orphanet: an online rare disease and orphan drug data base.

Taurodontia-absent teeth-sparse hair syndrome. ORPHA:2731

This syndrome is characterised by cong enital absence of the teeth, and sparse or absent hair. Taurodontia is also present in the majority of cases. The syndrome has been described in less than 15 patients from different families. 